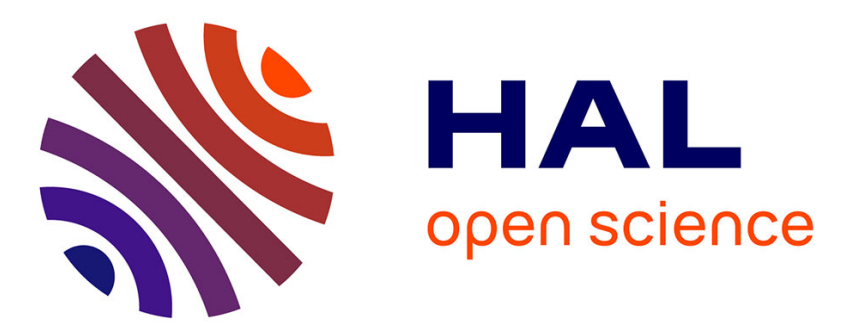

\title{
Topographical and nanomechanical characterization of casein nanogel particles using atomic force microscopy
} Asma Bahri, Marta Martin, Csilla Gergely, Sylvie Marchesseau, Dominique Chevalier-Lucia

\section{- To cite this version:}

Asma Bahri, Marta Martin, Csilla Gergely, Sylvie Marchesseau, Dominique Chevalier-Lucia. Topographical and nanomechanical characterization of casein nanogel particles using atomic force microscopy. Food Hydrocolloids, 2018, 83, pp.53-60. 10.1016/j.foodhyd.2018.03.029 . hal-01793780

\section{HAL Id: hal-01793780 \\ https://hal.science/hal-01793780}

Submitted on 26 May 2020

HAL is a multi-disciplinary open access archive for the deposit and dissemination of scientific research documents, whether they are published or not. The documents may come from teaching and research institutions in France or abroad, or from public or private research centers.
L'archive ouverte pluridisciplinaire HAL, est destinée au dépôt et à la diffusion de documents scientifiques de niveau recherche, publiés ou non, émanant des établissements d'enseignement et de recherche français ou étrangers, des laboratoires publics ou privés.

\section{(c)(1)}

Distributed under a Creative Commons Attribution| 4.0 International License 


\section{Accepted Manuscript}

Topographical and nanomechanical characterization of casein nanogel particles using atomic force microscopy

Asma Bahri, Marta Martin, Csilla Gergely, Sylvie Marchesseau, Dominique ChevalierLucia

PII:

S0268-005X(17)32061-1

DOI:

10.1016/j.foodhyd.2018.03.029

Reference: FOOHYD 4340

To appear in: Food Hydrocolloids

Received Date: 13 December 2017

Revised Date: 14 March 2018

Accepted Date: 14 March 2018

Please cite this article as: Bahri, A., Martin, M., Gergely, C., Marchesseau, S., Chevalier-Lucia, D., Topographical and nanomechanical characterization of casein nanogel particles using atomic force microscopy, Food Hydrocolloids (2018), doi: 10.1016/j.foodhyd.2018.03.029.

This is a PDF file of an unedited manuscript that has been accepted for publication. As a service to our customers we are providing this early version of the manuscript. The manuscript will undergo copyediting, typesetting, and review of the resulting proof before it is published in its final form. Please note that during the production process errors may be discovered which could affect the content, and all legal disclaimers that apply to the journal pertain. 


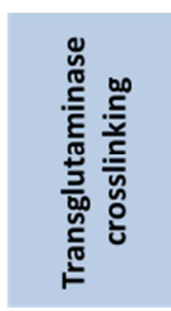

$\sum_{4}^{4}$
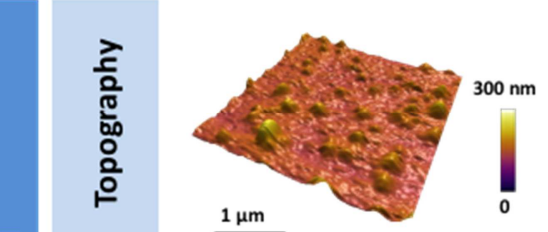

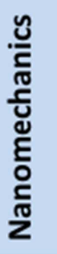

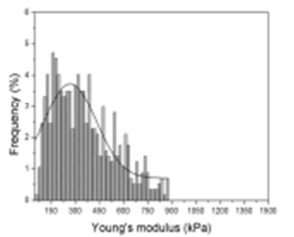

Transglutaminase

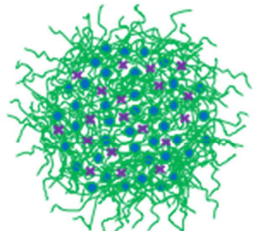

Transglutaminase crosslinked casein micelle
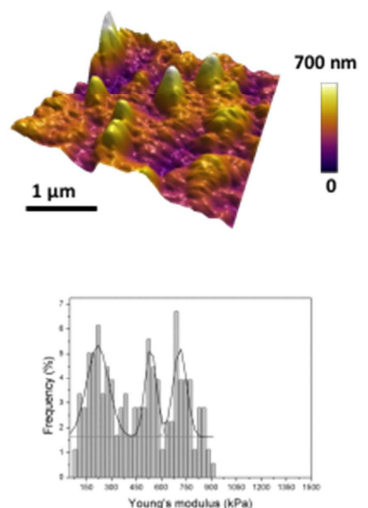


\section{Topographical and nanomechanical characterization of casein nanogel}

\section{2 particles using atomic force microscopy}

4 Asma Bahri $^{\mathrm{a}}$, Marta Martin ${ }^{\mathrm{b}}$, Csilla Gergely ${ }^{\mathrm{b}}$, Sylvie Marchesseau ${ }^{\mathrm{a}}$, Dominique Chevalier-

5 Lucia $^{\mathrm{a}^{*}}$

6 a IATE, Université de Montpellier, CIRAD, INRA, Montpellier SupAgro, Montpellier,

$7 \quad$ France

$8 \quad$ b L2C, Université de Montpellier, CNRS, Montpellier, France

$9 \quad$ * Corresponding author:

10 dominique.chevalier-lucia@umontpellier.fr

11 Université de Montpellier

CC023 - UMR IATE

13 Place Eugène Bataillon

1434095 Montpellier cedex 5 - France

15

16

17

\section{Abstract}

Casein micelle $(\mathrm{CM})$, porous colloidal phosphoprotein-mineral complex, naturally present in milk to deliver minerals, also has several features, which could ensure its use as nanocarrier for bioactives. CM structure being not steady according to the physico-chemical conditions, its stability can be improved by intra-micellar cross-linking using transglutaminase (TGase) inducing a strengthened structure called casein nanogel. The aim of this research was to investigate the morphology and nanomechanics of casein nanogel particles cross-linked by TGase (TG-CM) using atomic force microscopy (AFM) in native-like liquid environment (lactose-free simulated milk ultrafiltrate, SMUF). Prior to AFM, TG-CM were captured by anti-phospho-Ser/Thr/Tyr monoclonal antibodies covalently bound to a gold-coated slide via 
26 carbodiimide chemistry. Surface topography and size properties evaluation revealed an

27 increase in size of TG-CM compared to native CM, TG-CM being characterized by a mean

28 width of $264 \pm 7 \mathrm{~nm}$ and a mean height of $111 \pm 5 \mathrm{~nm}$. TG-CM displayed a relatively high

29 contact angle $\left(62^{\circ}\right)$ indicating a limited flattening of these particles after adsorption on the

30 substrate. The TG-CM elasticity was then evaluated applying low indentation forces on single

31 TG-CM. The TGase treatment led to a significant modification of $\mathrm{CM}$ nanomechanics

32 attributed to intramolecular rearrangements within the micellar structure. The elasticity

33 distribution of TG-CM revealed three elasticity peaks centered at $219 \pm 14 \mathrm{kPa}, 536 \pm 14 \mathrm{kPa}$

34 and $711 \pm 11 \mathrm{kPa}$. The lower elasticity peak is related to the native $\mathrm{CM}$ elasticity 35 characteristic and the two stiffer peaks were attributed to the substantial changes in the TG36 CM structure.

38 Keywords: Casein micelle; Nanogel; Transglutaminase; Atomic force microscopy;

39 Topography; Nanomechanics

40 


\section{Introduction}

With the growing awareness of food importance on disease prevention and cure, novel strategies have been developed to include and deliver bioactive compounds through food matrices (Katouzian \& Jaffary, 2016; Prakash \& van Boekel, 2010; Zhu, 2017). Particularly, nanoencapsulation of bioactives has been proposed to protect them against degradation during processing, increase their bioavailability and monitor their release to the desired site after ingestion (Katouzian \& Jaffary, 2016). Casein micelles (CM) are natural polymeric nanocarriers for delivery of minerals, particularly calcium and phosphate (de Kruif \& Holt, 2003). Consequently, bioactives delivery systems have been developed from nanosized native CM or modified CM (Chevalier-Lucia, Blayo, Gracià-Julià, Picart-Palmade, \& Dumay, 2011; Livney, 2010; Ranadheera, Liyanaarachchi, Chandrapala, Dissanayake, \& Vasiljevic, 2016). $\mathrm{CM}$ is a naturally self-assembly of caseins, major milk proteins ( 80\%), through hydrophobic bonds and colloidal calcium phosphate bridges. The main four caseins $\alpha_{\mathrm{s} 1}, \alpha_{\mathrm{s} 2}, \beta$ and $\kappa$ are phosphoproteins present at a molar ratio of $\sim 4: 1: 4: 1.6$ in $\mathrm{CM}$ (Walstra, Geurts, Noomen, Jellema, \& van Boekel, 1999). CM has a hydrodynamic diameter of $\sim 200 \mathrm{~nm}$ and a highly hydrated structure retaining $~ 3.7 \mathrm{~g}$ water/g of dry casein (McMahon \& Brown, 1984). It is characterized by a hydrophobic core and a hydrophilic shell, CM surface being covered by a $\kappa$-casein brush insuring its stability thanks to electrostatic and steric repulsion (Dalgleish, Horne, \& Law, 1989; De Kruif \& Zhulina, 1996; Horne, 2006). Moreover, the porous and open structure of $\mathrm{CM}$ due to the high proline content provides an excellent release mechanism for bioactive delivery in the stomach (Fox, 2003; Livney, 2010). Consequently, CM can be an excellent matrix to carry hydrophobic molecules and other biopolymers (Ranadheera et al., 2016). Caseins without a well-defined permanent second or tertiary structure have been described as rheomorphic (Holt \& Sawyer, 1993) meaning that they may adapt their structure to suit various conditions. CM structure is therefore not steady since several structural 
modifications can occur and even lead to the disruption of the CM framework due to changes of physico-chemical parameters such as $\mathrm{pH}$, ionic strength, water activity, temperature or pressure (De La Fuente, 1998; Gaucheron, 2005). However, CM structural stability can be improved by intra-micellar cross-linking using transglutaminase enzyme (TGase) to form strengthened structures called casein nanogel particles (De Kruif, Huppertz, Urban, \& Petukhov, 2012; Huppertz \& de Kruif, 2008; Smiddy, Martin, Kelly, de Kruif, \& Huppertz, 2006).

TGase has several applications in food processing aiming to enhance functional properties of proteins (Romeih \& Walker, 2017; Yokoyama, Nio, \& Kikuchi, 2004) by catalyzing covalent binding between protein-bound glutaminyl side chain and protein-bound lysyl side chain (Motoki, Seguro, Nio, \& Takinami, 1986). It has been clearly shown that TGase cross-linking increases the stability of CM against dissociating agents (Smiddy et al., 2006), ethanol coagulation (Huppertz \& De Kruif, 2007a) and heat treatment (O'Sullivan, Kelly, \& Fox, 2002). Particularly, many studies have focused on the major gel property modifications obtained from TGase cross-linked CM (Ardelean, Jaros, \& Rohm, 2013; Jaros, Jacob, Otto, \& Rohm, 2010; Lorenzen, Neve, Mautner, \& Schlimme, 2002). However, up to now, the topographical and nanomechanical properties of individual TG-CM have never been investigated.

The aim of the present research is to evaluate the morphology and nanomechanics of TGase cross-linked CM (TG-CM) using atomic force microscopy (AFM) in lactose-free simulated milk ultrafiltrate (SMUF, pH 6.6) to replicate the native mineral environment of CM (Jenness \& Koops, 1962). This technique provides soft material evaluation with minimal sample preparation to preserve its native properties (Jiao \& Scha, 2004; Kasas, Longo, \& Dietler, 2013). Nevertheless, AFM requires the immobilization of samples on a flat surface prior to study. In this work, CM and TG-CM were captured before AFM by weak interactions via a 
specific MAH-PSer/Thr/Tyr antibody covalently bound to a carboxylic acid self-assembled monolayer on a gold surface. This capture method was previously developed and tested on native casein micelles (Bahri et al., 2017). The characterization of TG-CM, individual internal cross-linked casein micelle, was carried out in parallel with that of native CM and was also intended to validate the sensitivity of this methodology to investigate the topographical and nanomechanical properties of casein micelles.

\section{Material and methods}

\subsection{Reagents}

Tri-potassium citrate, tri-sodium citrate, $\mathrm{KH}_{2} \mathrm{PO}_{4}, \mathrm{~K}_{2} \mathrm{SO}_{4}$ were purchased from Alfa Aesar (Heysham, UK). $\mathrm{K}_{2} \mathrm{CO}_{3}$ and $\mathrm{CaCl}_{2}$ were from Amresco (Solon, Ohio, USA) and acetic acid, $\mathrm{MgCl}_{2}, \mathrm{KCl}$ and $\mathrm{KOH}$ from VWR BDH Prolabo (Fontenay-sous-bois, France). 11-mercapto1-undecanoic acid (11-MUA), N-ethyl-dimethylaminopropylcarbodiimide (EDC), Nhydroxysuccinimide (NHS) and sodium azide were obtained from Sigma-Aldrich (SaintQuentin Fallavier, France). Sodium acetate was purchased from Merck (Darmstadt, Germany). Transglutaminase (TGase, Activa WM®) was a gift from Ajinomoto Foods Europe S.A.S. (Mesnil-Saint-Nicaise, France). Mouse anti-human phospho-Ser/Thr/Tyr monoclonal antibody (MAH-PSer/Thr/Tyr antibody) was from Spring Bioscience (E3074 Pleasanton, CA, USA). HBS-N buffer (0.01 M HEPES, $0.15 \mathrm{M} \mathrm{NaCl}, \mathrm{pH} 7.4$ ) and ethanolamine hydrochloride $1 \mathrm{M}$ pH 8.5 were purchased from Biacore (GE Healthcare, Velizy-Villacoublay, France). All solutions were prepared using Milli-Q water (Millipore®).

\subsection{Preparation of native and cross-linked casein micelle dispersions}

Native phosphocasein (PC) powder purchased from Ingredia SA (Promilk 852B, lot 131088, Arras, France) has been industrially obtained by microfiltration and diafiltration using the 
116 milk mineral soluble phase ensuring a quasi-native state to the prepared casein micelles. PC

117 powder contained $95 \mathrm{~g}$ dry solids per $100 \mathrm{~g}$ of powder and, in dry basis (w/w), 86\% total 118 proteins (corresponding to $79.1 \%$ caseins).

119 Casein micelle dispersion $(5 \%, \mathrm{w} / \mathrm{w})$ was prepared by dissolving PC powder in $\mathrm{pH} 6.6$

120 lactose-free simulated milk ultrafiltrate (SMUF), replicating the mineral environment of 121 native CM (Jenness \& Koops, 1962). The dispersion was stirred at $540 \mathrm{rpm}$ for $30 \mathrm{~min}$ at 20

$122{ }^{\circ} \mathrm{C}$ before being stored overnight at $4{ }^{\circ} \mathrm{C}$ improving powder hydration. The PC dispersion was 123 then warmed at $40{ }^{\circ} \mathrm{C}$ for $1 \mathrm{~h}$ and rapidly cooled to $20^{\circ} \mathrm{C}$ just before experiments to ensure 124 complete equilibration. To prevent microbial growth, sodium azide $(0.35 \mathrm{~g} / \mathrm{L})$ was added to 125 all samples.

126 CM cross-linked by TGase (TG-CM) were obtained from PC dispersion prepared as 127 described above, equilibrated at $30{ }^{\circ} \mathrm{C}$ for $2 \mathrm{~h}$ and then incubated with $0.5 \mathrm{~g} / \mathrm{L}$ TGase (100 $128 \mathrm{U} / \mathrm{g}$ activity) at $30{ }^{\circ} \mathrm{C}$ for $24 \mathrm{~h}$. Then, TGase was inactivated by heating the dispersion at 70

$129{ }^{\circ} \mathrm{C}$ for $10 \mathrm{~min}$, followed by a rapid cooling to room temperature in an ice-water bath (Smiddy 130 et al., 2006). The cross-linkage of CM by TGase was checked by investigating the CM 131 demineralization by sodium citrate addition up to $100 \mathrm{mmol} \cdot \mathrm{L}^{-1}$ and turbidity measurements at $132633 \mathrm{~nm}$ (Huppertz, Smiddy, \& de Kruif, 2007) as shown in Table S1. A PC control dispersion 133 was concurrently prepared following the same thermal history as TG-CM but without 134 addition of TGase.

\subsection{Micelle size distribution by photon correlation spectroscopy}

137 The CM size distribution was evaluated by photon correlation spectroscopy (PCS) using a 138 Zetasizer Nano-ZS equipment (Malvern Instruments, Malvern, UK) at $25{ }^{\circ} \mathrm{C}$. Before 139 analyses, each sample was diluted 20-fold with SMUF to avoid multiple diffusion phenomena 140 during PCS measurement. Experimental data were assessed by the NNLS algorithm with the 
141 dispersant viscosity taken as $0.89 \mathrm{mPa} . \mathrm{s}$ and the refractive index as 1.33 at $25{ }^{\circ} \mathrm{C}$.

142 Characteristics of the dispersed CM particles were taken as for milk proteins: 0.004 and 1.36

143 for the imaginary and the real refractive indices, respectively (Regnault, Thiebaud, Dumay, \&

144 Cheftel, 2004). For each independent sample, a mean distribution curve in intensity and in

145 number was calculated from six measurements as well as the mean diameter (arithmetical 146 mean).

\subsection{Scanning electron microscopy (SEM)}

149 Scanning electron microscopy (SEM) was used to evaluate CM shape. SEM samples were

150 prepared as described in a previous work (Gastaldi, Lagaude, \& De La Fuente, 1996). Briefly, 151 ANODISC $®$ membranes (Whatman, Maidstone, England) with an average pore diameter of $152200 \mathrm{~nm}$ were immersed overnight in CM dispersion. After dehydration in a series of graded 153 ethanol solutions (25-100\%), the specimens were dried using a critical point dryer (Bal-Tec 154 AG, Balzers, Liechtenstein, Germany). Then, the patterns were sputtered with gold palladium 155 and analyzed with a Hitachi S-4800 scanning electron microscope at an accelerating voltage 156 of $2 \mathrm{kV}$.

157

$158 \quad$ 2.5. Atomic force microscopy

159 2.5.1. CM capture for AFM experiment

$160 \mathrm{CM}$ were captured by low energy interactions via MAH-PSer/Thr/Tyr antibody as described

161 in a previous work (Bahri et al., 2017). All immobilization steps were carried out at room

162 temperature. As a first step, a gold-sputtered glass chip (AU.0500.ALSI, Platypus

163 Technologies LLC, Madison, WI, USA) was chemically cleaned twice with piranha solution

$164\left(70 \% \mathrm{H}_{2} \mathrm{SO}_{4}\right.$ plus $\left.30 \% \mathrm{H}_{2} \mathrm{O}_{2}\right)$, then three times with ethanol. The cleaned chip was 165 immediately immersed in an ethanolic solution of 11-MUA $(5 \mathrm{mM})$ for $18 \mathrm{~h}$ to coat the 
166 surface with a self-assembled monolayer (SAM) of carboxyl groups. The chip was then

167 extensively rinsed with absolute ethanol and ultrapure water before being immersed for $1 \mathrm{~h}$ in

168 a MAH-PSer/Thr/Tyr antibody solution $(50 \mu \mathrm{g} / \mathrm{mL})$ prepared in acetate buffer $(10 \mathrm{mM}, \mathrm{pH}$

169 5). It was rinsed with acetate buffer $(10 \mathrm{mM}, \mathrm{pH}$ 5), then with HBS-N buffer (0.01 M HEPES,

$170 \quad 0.15 \mathrm{M} \mathrm{NaCl}, \mathrm{pH} 7.4)$ before immersion into ethanolamine solution (1 M, pH 8) for 30 min to

171 block free binding sites. The prepared chip was then immediately immersed into the TG-CM

172 dispersion for $1 \mathrm{~h}$, rinsed with SMUF and equilibrated for $4 \mathrm{~h}$ at room temperature before

173 AFM measurements.

174 2.5.2. AFM measurements

175 The AFM experimental system used was an Asylum MFP-3D head coupled to the Molecular

176 Force Probe 3D controller (Asylum Research, Santa Barbara, CA, USA). The microscope was

177 placed in an acoustic isolation enclosure with an anti-vibration system. Silicon nitride

178 cantilevers MLCT were purchased from Veeco Metrology Group (Santa Barbara, CA, USA),

179 with a nominal spring constant of $0.01 \mathrm{~N} . \mathrm{m}^{-1}$ and an half-opening angle of $35^{\circ}$. Prior to each

180 experiment, the cantilever spring constant was determined in liquid environment using the

181 thermal noise method included in the MFP-3D software. AFM height, deflection trace and

182 retrace topographic images, with a pixel resolution of 256 pixels at a line rate of $0.6 \mathrm{~Hz}$, were

183 obtained in contact mode in SMUF at room temperature. After testing a range of loading

184 forces on different individual TG-CM, measurements were performed with a maximum

185 loading force of $\sim 100 \mathrm{pN}$. Higher loading force values led to stiffness overestimation due to

186 the substrate. It was particularly checked that CM and TG-CM retained the same spherical

187 cap section shape and remained adhered before and after indentation experiments (Figure S1).

188 A constant approach velocity of $6 \mu \mathrm{m} . \mathrm{s}^{-1}$ was used, meaning a piezo-extension rate of $3 \mathrm{~Hz}$ to

189 minimize hydrodynamic and viscoelastic artifacts (Rosenbluth, Lam, \& Fletcher, 2006). 
The height (h) and width (w) distributions were obtained from the single TG-CM size analysis using the MFP-3D software. The contact angle $(\theta)$ of each TG-CM was deduced

192 from the AFM-measured height and width using the equation (1):

$$
\theta=180 \operatorname{Arccos}(1-(\mathrm{h} / \mathrm{w})) / \pi
$$

194 The elastic deformation was obtained from the force curves as a function of the loading force

195 applied by the tip. The Young's modulus (E) was calculated for each force curve from the 196 approaching part of the curve according to a modified Hertz model (Hertz, 1881), as 197 described by Martin et al. (2013).

198 Experiments were repeated 3 times on different AFM gold chips.

199

200

201

202

203

204

205

206 analyzed by the Student's t-test. Statistical significance was set at $p<0.05$.

\subsubsection{AFM data analysis}

Raw images were corrected by an implemented Asylum software using a standard procedure (flatten, planefit and artifact lines caused by the tip attachement and removal). Longitudinal individual elasticity values for a sample were collected via the Asylum software providing the distribution of elasticity values. Counts were normalized considering the total collected elasticity values of the specimen. A Gaussian fitting was then applied using the multi-peak analyzing software implemented in the MFP-3D operating system and OriginPro 8 software.

\subsection{Statistics}

Results were expressed as mean \pm standard deviation. All the AFM and PCS results were profiles at selected zones were also obtained by the software. The scale indicating the sample height or deflection was adjusted to limit the gap between high and low regions. The

\section{Results and discussion}




\subsection{Topography of transglutamisase cross-linked CM}

216 The influence of TG cross-linking has been evaluated on the apparent CM shape and

217 dimensions. Fig. 1a-h shows AFM height and deflection images of CM and TG cross-linked

218 CM captured on SAM-gold substrate via MAH-PSer/Thr/Tyr antibody when imaged in

219 contact mode under native conditions (SMUF, pH 6.6). Scan parameters were adjusted for

220 optimum contrast and stability and no lateral displacement of particles was recorded during

221 analyses. These images (Fig. 1a-h) emphasize the efficiency of specific antibody capture of

222 TG-CM that reveal a spherical cap shape, as already observed for native CM (Bahri et al.,

223 2017). The native $\mathrm{CM}$ and TG-CM surface appears topographically homogeneous. This

224 observation was confirmed by SEM micrographs (Fig. 2), which display different-sized CM

225 and TG-CM (range of 40-300 $\mathrm{nm}$ ) with a typical spherical shape and a rough surface.

226 Moreover, SEM images of TG-CM (Fig. 2b, d) do not show the presence of CM aggregates

227 proving that TGase cross-linking is exclusively intra-micellar.

228 According to the 2D and 3D AFM heights (Fig. 1a, c, e, g, h, j, l), it appeared that TG-CM are

229 higher and wider than native CM. The surface coverage of TG-CM $\left(11 \pm 4\right.$ micelles/ $\left.\mu \mathrm{m}^{2}\right)$ was

230 significantly $(p<0.05)$ lower than the native CM surface coverage $\left(20 \pm 2\right.$ micelles $\left./ \mu \mathrm{m}^{2}\right)$, this

231 lower density being attributed to the smaller size of native CM compared to TG-CM. At the

232 same time, the hydrodynamic diameter distribution curves of native CM and TG-CM

233 measured by PCS have been compared. The both size distribution curves in intensity exhibit

234 monomodal and polydisperse populations (Fig. 3). TG-CM have however a significantly ( $p<$

235 0.05) higher average hydrodynamic diameter of $214 \pm 8 \mathrm{~nm}$ compared to $192 \pm 8 \mathrm{~nm}$ for 236 native $\mathrm{CM}$.

237 This result was confirmed by the height and width distributions (Fig. 4a, b) obtained from the 238 single TG-CM size analysis using the MFP-3D software. All in all, 250 features obtained 239 from 10 different 2D-AFM images were analyzed. The size counts were normalized 
considering the total collected values of samples. A multi-peak fitting was then applied using

241 OriginPro 8 software to calculate the mean width and height. As depicted in Fig. 4a, b, TG-

$242 \mathrm{CM}$ are polydisperse with monomodal width and height distributions and they are significantly $(p<0.05)$ wider $(264 \pm 7 \mathrm{~nm})$ and higher $(111 \pm 5 \mathrm{~nm})$ than native CM

244 investigated in the same conditions and characterized by a mean width of $148 \pm 8 \mathrm{~nm}$ and a 245 mean height of $42 \pm 1 \mathrm{~nm}$ (Bahri et al., 2017).

246 The morphological AFM results as those from SEM strongly show that TGase cross-linking is 247 intra- and not inter-micellar, which is in good agreement with previous studies that underlined 248 the intra-micellar cross-linking of native CM using different methods such as PCS, SLS and 249 SAXS (Huppertz \& De Kruif, 2008). However, it has been until now mentioned that CM size 250 was not modified by TGase cross-linking. Nevertheless, the present results obtained from 251 AFM and PCS data indicate that TGase cross-linking increases CM size as also observed 252 previously on covalently cross-linked CM using genipin (Nogueira Silva, Bahri, Guyomarc'h, Beaucher, \& Gaucheron, 2015). On the other hand, from SEM images (Fig. 2), the size difference between native $\mathrm{CM}$ and TG-CM was not clearly observable. This phenomenon could be attributed to $\mathrm{CM}$ shrinkage caused by the critical point drying of samples during the preparation steps since $\mathrm{CM}$ are highly hydrated features and therefore, drying process has an important impact on micellar structure. These observations are in accordance with other studies reporting distortion of $\mathrm{CM}$ particles due to the drying step during sample preparation for SEM (Dalgleish, Spagnuolo, \& Goff, 2004; Martin, Goff, Smith, \& Dalgleish, 2006; 260 McMahon \& Oommen, 2008).

261 AFM size characteristics were used to calculate the native CM and TG-CM volume; it should 262 remain constant even after particle adsorption upon the surface (Evangelopoulos, Glynos, \& 263 Koutsos, 2012). The volume of the TG-CM was then calculated using MFP-3D software by 264 performing the sum of all the heights of the micelle multiplied by the $\mathrm{X}$ scale and Y scale. 
265 TG-CM have a volume of $\sim 5 \mathrm{x} 10^{6} \mathrm{~nm}^{3}$ that higher than that measured for native $\mathrm{CM}(\sim 1 \mathrm{x}$ $26610^{6} \mathrm{~nm}^{3}$ ), leading to a mean diameter of $214 \mathrm{~nm}$ for TG-CM and $123 \mathrm{~nm}$ for native CM 267 considering CM as spherical. These values are consistent with the hydrodynamic diameter 268 obtained by PCS for TG-CM.

269 Height and width distributions (Fig. 4a, b) show that TG-CM captured on SAM-gold substrate 270 via MAH-PSer/Thr/Tyr antibody were definitely larger than higher, as it was also the case for native CM (Bahri et al., 2017). According to AFM size data, native CM and TG-CM have the shape of a spherical cap section rather than a sphere. This deformation, attributed to the adsorption upon gold substrate, can be evaluated by the ratio calculation between height and width, the perfect spherical particle width being equal to its height $(\mathrm{h} / \mathrm{w} \sim 1)$. TG-CM data reveal a $\mathrm{h} / \mathrm{w}$ ratio of $\sim 0.5$ higher than the native $\mathrm{CM}$ ratio $(\sim 0.3)$, indicating that native $\mathrm{CM}$ have a flatter shape compared to TG-CM. A previous study also evaluated the $\mathrm{h} / \mathrm{w}$ ratio equal to 0.3 for native $\mathrm{CM}$ in liquid conditions and also highlighted $\mathrm{CM}$ deformation due to attachment on the substrate without losing volume in the case of CM immobilization on gold substrate via amine-coupling strategy (Ouanezar, Guyomarc'h, \& Bouchoux, 2012). The h/w 280 ratio of native CM and TG-CM implies a liquid droplet like behavior (Helstad et al., 2007). This deformation can also be displayed by plotting the height against the width for each single object (Fig. 4c, d). The comparison with the dotted line representing a perfect sphere points towards the fact that the TG-CM (Fig. 4c) are less flattened compared to native CM (Fig. 4d) 284 once captured on the gold substrate. This phenomenon clearly highlights a structural 285 strengthening of CM due to the molecular rearrangements induced by TGase. to the drop interface at the apparent intersection of these interfaces describes the object deformation upon adsorption (Brown, 1999; Russel, 2009 ). A small contact angle is observed 
when the particle spreads on the surface, while a large contact angle is observed when the

291 liquid beads on the surface. More specifically, a perfect spherical particle would exhibit a contact angle greater than $90^{\circ}$ (Yuehua \& Randall, 2013). The equilibrium shape of a given particle does not depend only on surface forces but is also greatly affected by the elastic modulus of the droplet, the droplet deformation depending of material elastic nature resulting from stress development across the bulk in opposition to that deformation (Brown, 1999;

Evangelopoulos et al., 2012). According to the AFM data analysis, TG-CM have a contact angle $\theta$ of $62^{\circ}$ against the coated surface. Conversely, native CM have a significantly ( $p<$ $0.05)$ lower contact angle value of $44^{\circ}$. These results confirm the observed less deformation of TG-CM than native CM after capture on gold substrate.

300 An important change of the CM topography and elastic properties occurred after CM cross301 linking with TGase compared to native CM. Cross-linked CM were significantly higher and larger than native $\mathrm{CM}$ pointing towards significant modifications in the $\mathrm{CM}$ structure due to TG crosslinking. A previous study highlighted a similar effect on CM height after crosslinking with genipin by AFM measurements in air, but widths were narrower probably due to dry condition (Nogueira Silva et al., 2015). Unlike control native CM, TG-CM were less deformed when adsorbed on gold substrate as reflected by a higher contact angle. aspect of TG-CM compared to native CM. The ratio $\mathrm{h} / \mathrm{w}$ confirmed this observation since it was higher than that evaluated for native CM.

\subsection{Nanomechanical properties of TG-CM}

312 To explore nanomechanical properties of CM, low indenting forces were applied on each

313 individual micellar object. CM kept the same shape and neither displacement nor

314 disintegration was recorded after indentation experiments. A low loading force value of $\sim 100$ 
$315 \mathrm{pN}$ was chosen for nanoindentation to avoid CM damage due to the AFM tip and ensure a

316 minimal deformation in the CM-substrate region. Ten force curves were applied at the center

317 of each individual CM. The elasticity of $\mathrm{CM}$ at a given position was then calculated by fitting

318 the approach part of the force curve using the Hertz model (Hertz, 1881; Uricanu, Duits, \&

319 Mellema, 2004) (Figure S2). In order to confirm the position of the analyzed particles,

320 successive images were regularly performed and compared (Figure S1). Furthermore, by

321 reducing the indentation to $20 \mathrm{~nm}$, the contribution of the hard substrate on the calculated

322 elasticity value was minimized. The elasticity of 20 micellar objects was calculated to obtain

323 about 200 elasticity values.

324 The histogram of TG-CM stiffness values (Fig. 5) reveals a multimodal stiffness distribution

325 with three prominent peaks at $218 \pm 14 \mathrm{kPa}, 536 \pm 10 \mathrm{kPa}$ and $711 \pm 11 \mathrm{kPa}$, as identified by

326 the peak analyzing software. The intensity of the three Gaussian distributions used to fit the

327 TG-CM histogram is similar suggesting that the three populations have the same weight (Fig.

328 5). In comparison, a broad unimodal stiffness distribution with a peak centered at $269 \pm 14$

$329 \mathrm{kPa}$ was observed for native immobilized CM (Fig. 5). Generally, the mechanical

330 heterogeneity of apparent Young's moduli is attributed to the complexity of the CM structure,

331 the AFM tip indenting different components of the outer layer or of the core of CM (Bahri et

332 al., 2017). Actually, hydrophobic bonds, negatively charged surface and calcium phosphate

333 nanoclusters are involved in this complexity. In the case of TG-CM, the softest stiffness peak

334 value $(218 \pm 14 \mathrm{kPa})$ is comparable to native CM Young's modulus value (269 $\mathrm{kPa} \pm 14 \mathrm{kPa})$,

335 and presumably represents a population with characteristics close to those of native CM. The

336 two other stiffer peaks $(535 \pm 10 \mathrm{kPa}$ and $710 \pm 11 \mathrm{kPa})$ were most likely due to substantial

337 changes in the shape and structure of CM induced by the TGase activity, as suggested by the

338 size and topographical AFM data. This modification could be attributed to the creation of new

339 casein dimers and oligomers formed by crosslinking peptide bound glutamine and lysine 
residues after incubation with TGase (Ardelean et al., 2013; Smiddy et al., 2006). It is

341 demonstrated that TGase creates intramicellar bonds; hence, $\kappa$-casein which is placed on the

342 surface of the $\mathrm{CM}$ is the most involved in the polymerization reaction started by TGase

343 followed by $\beta$ and $\alpha_{\mathrm{s}}$ casein, respectively (Ardelean et al., 2013; Huppertz \& de Kruif, 2007a,

344 2007b; Jaros et al., 2010; Sharma, Lorenzen, \& Qvist, 2001). This is probably related to the

345 respective locations of caseins within the $\mathrm{CM}$ since $\mathrm{CM}$ is recognized as complex network of

346 caseins chains with $\kappa$-casein hairy layer predominately present on the surface while $\beta$-casein

347 is mostly present in the interior and $\alpha_{\mathrm{s}}$-casein is located all over the structure (Dalgleish \&

348 Corredig, 2012; De Kruif \& Holt, 2003; Marchin, Putaux, Pignon, \& Léonil, 2007).

349 To date, there are very few studies in literature on the effect of TGase cross-linking on the 350 elasticity of individual CM at nanoscopic scale. Nieuwland, Bouwman, Bennink, Silletti, \& 351 de Jongh (2015) investigated the elastic modulus of individual CM cross-linked by TGase at different concentrations (0 to $90 \mathrm{U} / \mathrm{g}$ ) using the Derjaguin, Muller, Toporov model applied on AFM force curves. The maximum modulus was observed for the highest TGase concentration, slightly lower than the TGase concentration fixed in this study. This is in accordance with the present results since the stiffness distribution of TG-CM was 356 characterized by two peaks $(536 \pm 10 \mathrm{kPa}$ and $711 \pm 11 \mathrm{kPa})$ stiffer than the native $\mathrm{CM}$ 357 Young's modulus value (269 kPa $\pm 14 \mathrm{kPa})$.

358 At macroscopic scale, the cross-linked TG-CM have been investigated focusing on TG-CM 359 gelling properties by rheological measurements, highlighting an increase in stiffness and 360 breaking strain of the TG-CM acid gels (Anema, Lauber, Lee, Henle, \& Klostermeyer, 2005;

361 Faergemand \& Qvist, 1997; Faergemand, Sorensen, Jorgensen, Budolfsen, \& Qvist, 1999; 362 Lauber, Henle, \& Klostermeyer, 2000). The gel microstructure modification observed in these 363 studies at the macroscopic scale is attributed to the introduction of new covalent bonds in 364 individual CM. This resulted at nanoscale in a higher stiffness of individual TG-CM 
compared to native $\mathrm{CM}$ as shown by AFM nanomechanical characterization indicating that

366 TGase modified the nanoscale organization of CM from colloids association to microgel 367 particles.

368 Besides, these AFM results on the nano-structural properties of individual CM after 369 enzymatic cross-linking highlight significant modifications probably inducing changes in the 370 functional properties of caseins.

\section{Conclusions}

373 In summary, this study of TG-CM by AFM in liquid environment presents the first

374 investigation on the size and nanomechanical properties of individual TG-CM. The AFM 2D 375 images reveal a spherical-cap shape with a wider $(264 \pm 7 \mathrm{~nm})$ and higher $(111 \pm 5 \mathrm{~nm})$ 376 structure than native CM. Moreover, TG-CM shows a more resistant structure upon 377 adsorption on gold substrate owing to a high contact angle of $62^{\circ}$.

378 The TG-CM nanomechanical properties highlight a low elasticity peak at $218 \pm 14 \mathrm{kPa}$ that 379 could correspond to the mechanical signature of native CM and also two stiffer elasticity 380 peaks observed at $536 \pm 10 \mathrm{kPa}$ and $711 \pm 11 \mathrm{kPa}$, most likely directly related to substantial 381 changes in the shape and structure of $\mathrm{CM}$ induced by TGase and responsible for the 382 modification of their functional properties.

383 These results support the improved stability of TG-CM suggesting that these nanogel particles 384 can be an excellent matrix for bioactives encapsulation.

\section{Acknowledgements}

387 We thank the French Ministry of Higher Education and Research for financial support and M. 
Transglutaminase Activa ${ }^{\circledR}$ WM was kindly provided by Ajinomoto Foods Europe S.A.S

390 (Mesnil-Saint-Nicaise, France).

391

\section{References}

393 Anema, S. G., Lauber, S., Lee, S. K., Henle, T., \& Klostermeyer, H. (2005). Rheological 394 properties of acid gels prepared from pressure- and transglutaminase-treated skim milk. Food Hydrocolloids, 19(5), 879-887.

Ardelean, A. I., Jaros, D., \& Rohm, H. (2013). Influence of microbial transglutaminase crosslinking on gelation kinetics and texture of acid gels made from whole goats and cows milk. Dairy Science and Technology, 93(1), 63-71.

Bahri, A., Martin, M., Gergely, C., Pugnière, M., Chevalier-Lucia, D., \& Marchesseau, S. (2017). Atomic force microscopy study of the topography and nanomechanics of casein micelles captured by an antibody. Langmuir, 33(19), 4720-4728.

Brown, R. (1999). Handbook of polymer testing (Marcel Dek). New York.

403

404

405

406

407

408

Chevalier-Lucia, D., Blayo, C., Grácia-Juliá, A., Picart-Palmade, L., \& Dumay, E. (2011). Processing of phosphocasein dispersions by dynamic high pressure: Effects on the dispersion physico-chemical characteristics and the binding of $\alpha$-tocopherol acetate to casein micelles. Innovative Food Science and Emerging Technologies, 12(4), 416-425.

Dalgleish, D. G., \& Corredig, M. (2012). The structure of the casein micelle of milk and Its changes during processing. Annual Review of Food Science and Technology, 3, 449-467.

Dalgleish, D., Horne, D. S., \& Law, A. J. R. (1989). Size-related differences in bovine casein micelles. Biochemica et Biophysica Acta, 991, 383-387.

Dalgleish, D. G., Spagnuolo, P. A., \& Goff, H.D. (2004). A possible structure of the casein micelle based on high-resolution field-emission scanning electron microscopy. International Dairy Journal, 14, 1025-1031. 
414 De Kruif, C. G., \& Holt, C. (2003). Casein micelle structure, functions and interactions. $415 \quad$ Advanced Dairy Chemistry, 1(3), 233-275.

416 De Kruif, C. G., \& Zhulina, E. B. (1996). $\kappa$-Casein as a polyelectrolyte brush on the surface 417 of casein micelles. Colloids and Surfaces A: Physicochemical and Engineering Aspects, $418 \quad 117(1-2), 151-159$.

419 De Kruif, C. G., Huppertz, T., Urban, V. S., \& Petukhov, A. V. (2012). Casein micelles and 420 their internal structure. Advances in Colloid and Interface Science, 171-172, 36-52.

De La Fuente, M. A. (1998). Changes in the mineral balance of milk submitted to technological treatments. Trends in Food Science and Technology, 9(7), 281-288.

Evangelopoulos, A. E. A. S., Glynos, E., \& Koutsos, V. (2012). Elastic Modulus of a Polymer Nanodroplet : Theory and Experiment. Langmuir, 10(28), 4754-4767.

Faergemand, M., \& Qvist, K. B. (1997). Transglutaminase: effect on rheological properties, microstructure and permeability of set style acid skim milk gel. Food Hydrocolloids, 11(3), 287-292.

Faergemand, M., Sorensen, M., Jorgensen, U., Budolfsen, G., \& Qvist, K. (1999). Transglutaminase: effect on instrumental and sensory texture of set style yoghurt. Milchwissenschaft-Milk Science International, 54, 563-566.

Fox, P. F. (2003). Milk proteins: general and historical aspects. In P. F. Fox \& P. L. H. McSweeney (Eds.), Advanced Dairy Chemistry: volume 1: Proteins, Parts A\&B (pp. 148). Springer US.

Gastaldi, E., Lagaude, A., \& De La Fuente, B. T. (1996). Micellar transition state in casein between pH 5.5 and 5.0. Journal of Food Science, 61(1), 59-64.

Gaucheron, F. (2005). The minerals of milk. Reproduction, Nutrition, Development, 45, 473483. 
like behaviour of whole casein aggregates adsorbed on graphite studied by nanoindentation with AFM. Food Hydrocolloids, 21(5-6), 726-738.

441 Hertz, H. (1881). Über die Berührung fester elastischer Körper. Journal Für Die Reine Und Angewandte Mathematik, 92, 156-171.

Holt, C., \& Sawyer, L. (1993). Caseins as rheomorphic proteins: interpretation of primary and secondary structures of the $\alpha$ s1-, $\beta$ - and $\kappa$-caseins. Journal of the Chemical Society, Faraday Transactions, 89(15), 2683-2692.

Horne, D. S. (2006). Casein micelle structure: Models and muddles. Current Opinion in Colloid \& Interface Science, 11(2-3), 148-153.

Huppertz, T., \& de Kruif, C. G. (2007a). Ethanol stability of casein micelles cross-linked with transglutaminase. International Dairy Journal, 17(5), 436-441.

Huppertz, T., \& de Kruif, C. G. (2007b). Rennet-induced coagulation of enzymatically crosslinked casein micelles. International Dairy Journal, 17(5), 442-447.

Huppertz, T., Smiddy, M. A., \& de Kruif, C. G. (2007). Biocompatible micro-gel particles from cross-linked casein micelles. Biomacromolecules, 8, 1300-1305.

Huppertz, T., \& de Kruif, C. G. (2008). Structure and stability of nanogel particles prepared by internal cross-linking of casein micelles. International Dairy Journal, 18(5), 556-565. milk ultrafiltrate. Netherlands Milk and Dairy Journal, 16, 153-164.

Jaros, D., Jacob, M., Otto, C., \& Rohm, H. (2010). Excessive cross-linking of caseins by microbial transglutaminase and its impact on physical properties of acidified milk gels. International Dairy Journal, 20(5), 321-327.

Jiao, Y., \& Scha, T. E. (2004). Accurate height and volume measurements on soft samples 462 with the atomic force microscope. Langmuir, 20, 10038-10045. 
explored by atomic force microscopy. Journal of Physics D-Applied Physics, 46,

465

466

467

468

469

470

471

472

473

474

475

476

477

478

479

480

481

482

483

484

485

486

487

488 133001.

Katouzian, I., \& Jafari, S.M. (2016). Nano-encapsulation as a promising approach for targeted delivery and controlled release of vitamins. Trends in Food Science \& Technology, 53, 34-48.

Lauber, S., Henle, T., \& Klostermeyer, H. (2000). Relationship between the crosslinking of caseins by transglutaminase and the gel strength of yoghurt. European Food Research and Technology, 210, 305-309.

Livney, Y. D. (2010). Milk proteins as vehicles for bioactives. Current Opinion in Colloid and Interface Science, 15(1-2), 73-83.

Lorenzen, P., Neve, H., Mautner, A., \& Schlimme, E. (2002). Effect of enzymatic crosslinking of milk proteins on functional properties of set-style yoghurt. International Journal of Dairy Technology, 55(3), 152-157.

Marchin, S., Putaux, J. L., Pignon, F., \& Léonil, J. (2007). Effects of the environmental factors on the casein micelle structure studied by cryo transmission electron microscopy and small-angle x-ray scattering/ultrasmall-angle x-ray scattering. Journal of Chemical Physics, 126(4), 045101.

Martin, M., Benzina, O., Szabo, V., Végh, A. G., Lucas, O., Cloitre, T., Scamps, F., \& Gergely, C. (2013). Morphology and nanomechanics of sensory neurons growth cones following peripheral nerve injury. Plos One, 8(2), 1-11.

Martin, A. H., Goff, D. H., Smith, A., \& Dalgleish, D. G. (2006). Immobilization of casein micelles for probing their structure and interactions with polysaccharides using scanning electron microscopy (SEM). Food Hydrocolloids, 20(6), 817-824.

McMahon, D. J., \& Brown, R. J. (1984). Composition, structure, and integrity of casein micelles: a review. Journal of Dairy Science, 67, 499-512. 
McMahon, D. J., \& Oommen, B. S. (2008). Supramolecular structure of the casein micelle. Journal of Dairy Science, 91(5), 1709-1721.

Motoki, M., Seguro, K., Nio, N., \& Takinami, T. (1986). Glutamine-specific deamidation of as1-casein by transglutaminase. Agricultural and Biological Chemistry, 50(12), 30253030.

Nieuwland, M., Bouwman, W. G., Bennink, M. L., Silletti, E., \& de Jongh, H. H. J. (2015). Characterizing length scales that determine the mechanical behavior of gels from crosslinked casein micelles. Food Biophysics, 10, 416-427.

497

498

499

500

501

502

503

504

505

506

507

508

509

510

511

512

513

Nogueira Silva, N. F., Bahri, A., Guyomarc'h, F., Beaucher, E., \& Gaucheron, F. (2015). AFM study of casein micelles cross-linked by genepin: effects of acid $\mathrm{pH}$ and citrate. Dairy Science and Technology, 95(1), 75-86.

O’Sullivan, M. M., Kelly, A. L., \& Fox, P. F. (2002). Effect of transglutaminase on the heat stability of milk: A possible mechanism. Journal of Dairy Science, 85(1), 1-7.

Ouanezar, M., Guyomarc'h, F., \& Bouchoux, A. (2012). AFM imaging of milk casein micelles: evidence for structural rearrangement upon acidification. Langmuir, 28, 49154919.

Prakash, V., \& van Boekel, M. A. J. S. (2010). Nutraceuticals: possible future ingredients and food safety aspects. In C. E. Boisrobert, A. Sjepanovic, S. Oh, \& H. L. M. Lelieveld (Eds.), Ensuring Global Food Safety (pp. 333-338). Oxford: University Press.

Ranadheera, C. S., Liyanaarachchi, W. S., Chandrapala, J., Dissanayake, M., \& Vasiljevic, T. (2016). Utilizing unique properties of caseins and the casein micelle for delivery of sensitive food ingredients and bioactives. Trends in Food Science and Technology, 57, $178-187$.

Regnault, S., Thiebaud, M., Dumay, E., \& Cheftel, J. C. (2004). Pressurisation of raw skim milk and of a dispersion of phosphocaseinate at $9{ }^{\circ} \mathrm{C}$ or $20^{\circ} \mathrm{C}$ : Effects on casein micelle 

size distribution. International Dairy Journal, 14(1), 55-68.

515 Romeih, E., \& Walker, G. (2017). Recent advances on microbial transglutaminase and dairy application. Trends in Food Science and Technology, 62,133-140.

517

518

Rosenbluth, M. J., Lam, W. A., \& Fletcher, D. A. (2006). Force microscopy of nonadherent cells : A comparison of leukemia cell deformability, 90(1762), 2994-3003.

Russel, S. (2009). Contact Angle Measurement Technique for Rough Surfaces. Michigan Technological University.

Sharma, R., Lorenzen, P. C., \& Qvist, K. B. (2001). Influence of transglutaminase treatment of skim milk on the formation of $\varepsilon$-(-glutamyl)lysine and the susceptibility of individual proteins towards crosslinking. International Dairy Journal, 11(10), 785-793.

Smiddy, M. A., Martin, J.E. G. H., Kelly, A. L., de Kruif, C. G., \& Huppertz, T. (2006). Stability of casein micelles cross-linked by transglutaminase. Journal of Dairy Science, 89(6), 1906-14.

Uricanu, V. I., Duits, M. H. G., \& Mellema, J. (2004). Hierarchical networks of casein proteins: An elasticity study based on atomic force microscopy. Langmuir, 20(12), 5079-5090.

Walstra, P., Geurts, T. J., Noomen, A., Jellema, A., \& van Boekel, M. A. J. S. (1999). Milk components. In P. Walstra, T. J. Geurts, A. Noomen, A. Jellema, \& M. A. J. S. van Boekel (Eds.), Dairy Technology (pp. 27-105). New York: Marcel Dekker.

Yokoyama, K., Nio, N., \& Kikuchi, Y. (2004). Properties and applications of microbial transglutaminase. Applied Microbiology and Biotechnology, 64(4), 447-454.

Yuehua, Y., \& Randall, L. (2013). Surface science techniques. In Springer Series in Surface Sciences (Vol. 51, pp. 3-34).

Zhu, F. (2017). Encapsulation and delivery of food ingredients using starch based systems. Food Chemistry, 229, 542-552. 
Figure captions

540 Figure 1: Native CM (a, b, e, f, i, j) and transglutaminase cross-linked CM (c, d, g, h, k, l)

541 topography. AFM height (a, c, e, g) and deflection (b, d, f, h) images, height profile (i, k) at

542 the selected black scan line on (e, g), three-dimensional AFM height image (j, l) of CM and

543 TG-CM CM. CM and TG-CM were captured on SAM via MAH-PSer/Thr/Tyr antibody.

544 Images were performed in liquid (SMUF, $\mathrm{pH}$ 6.6) in contact mode. The white scale bar (a-h)

545 represents $1 \mu \mathrm{m}$. The colored scale bar $(\mathrm{a}, \mathrm{c}, \mathrm{e}, \mathrm{g})$ represents the height range between 0 and

$546120 \mathrm{~nm}$. The grey scale bar $(\mathrm{b}, \mathrm{d}, \mathrm{f}, \mathrm{h})$ represents the deflection range between 0 and $30 \mathrm{~nm}$.

548 Figure 2: SEM images of native CM (a, c) and transglutaminase cross-linked CM (b, d) on 549 ANODISC $®$ membrane at two different magnifications.

Figure 3: Particle size distribution curves of native (ם) and TG cross-linked $(\bullet) \mathrm{CM}(5 \%$, $552 \mathrm{w} / \mathrm{w}$ ) determined by photon correlation spectroscopy (PCS) in light intensity. PCS 553 measurements were carried out at $25{ }^{\circ} \mathrm{C}$. Mean curves from six PCS determinations are 554 shown.

556 Figure 4: Histograms of width (a) and height (b) and height versus width plots (c-d) for TG

557 cross-linked (a, b, c) and native (d) CM. Height and width histograms were best fitted with a 558 Gaussian function. The dotted lines in the height vs width plots show the linear ratio between 559 width and height of a perfectly spherical particles.

560

561 Figure 5: AFM elasticity distribution indicating the stiffness of TG-CM in a liquid native

562 environment (SMUF, $\mathrm{pH}$ 6.6). Young's modulus (E) distribution was best fitted with 3

563 Gaussian peaks centered at $218 \pm 14 \mathrm{kPa}, 536 \pm 10 \mathrm{kPa}$ and $711 \pm 11 \mathrm{kPa}$ (solid line). 
564 Young's modulus distribution fit of native CM is proposed (dotted line) centered at $269 \pm 14$

$565 \mathrm{kPa}$. 10 loading forces were applied on 20 different CM in order to obtain 200 analyzed 566 curves. 
Figure 1
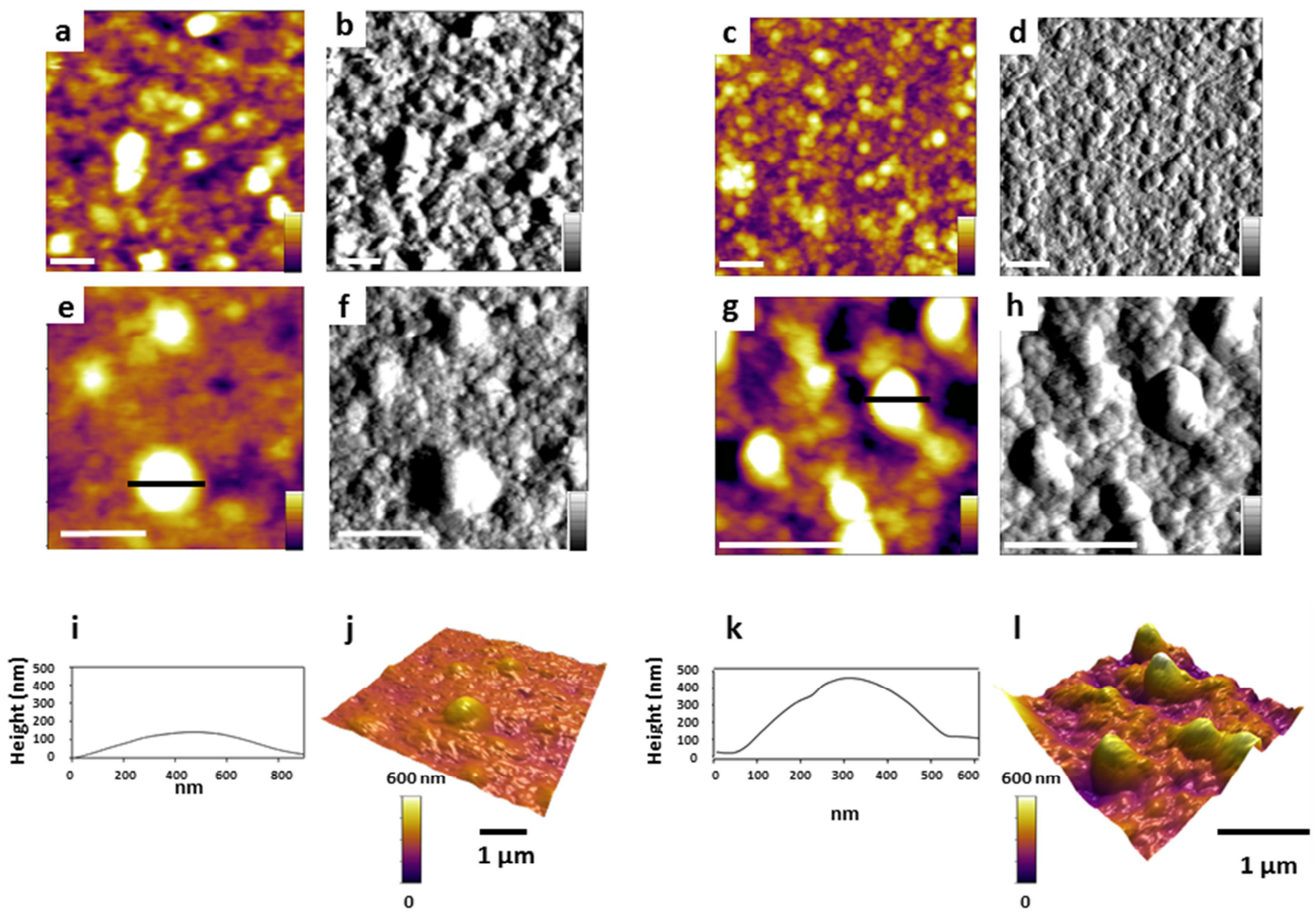
Figure 2
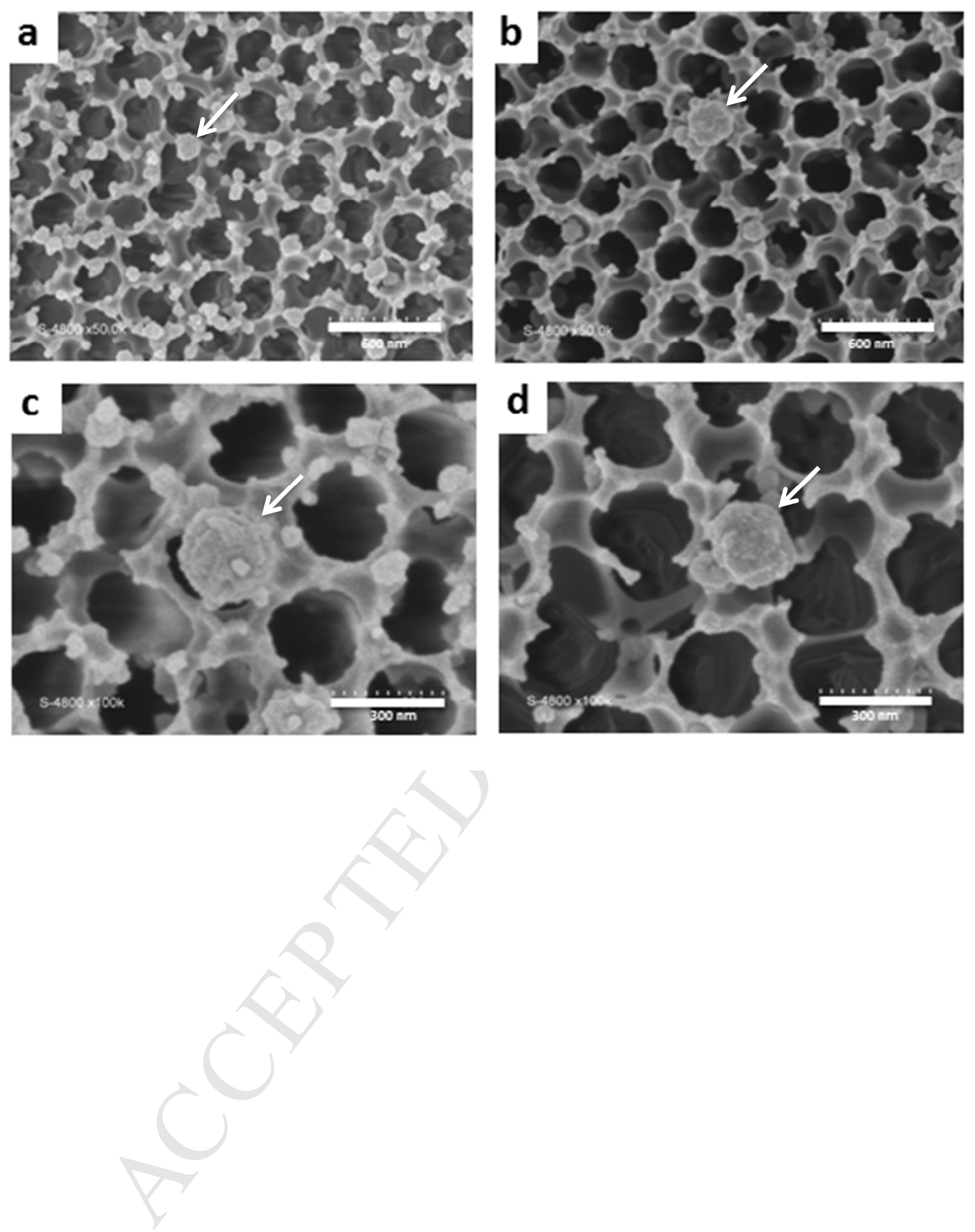
Figure 3

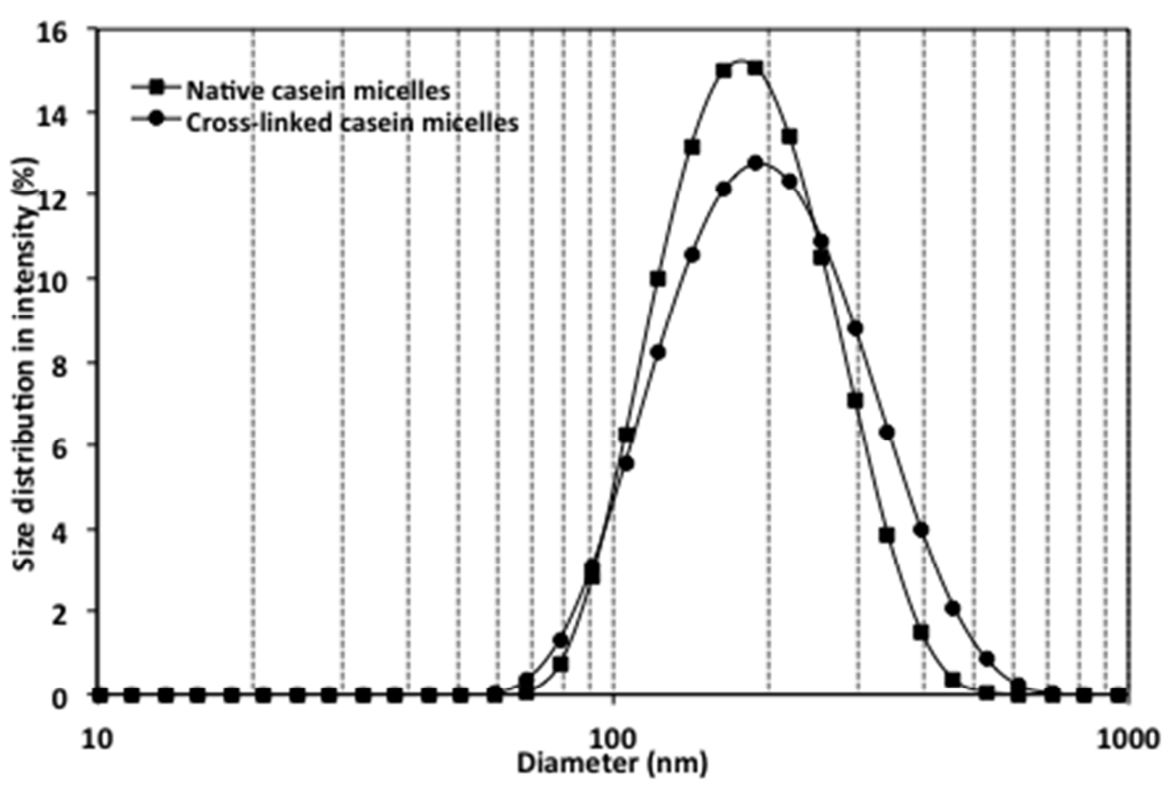


Figure 4
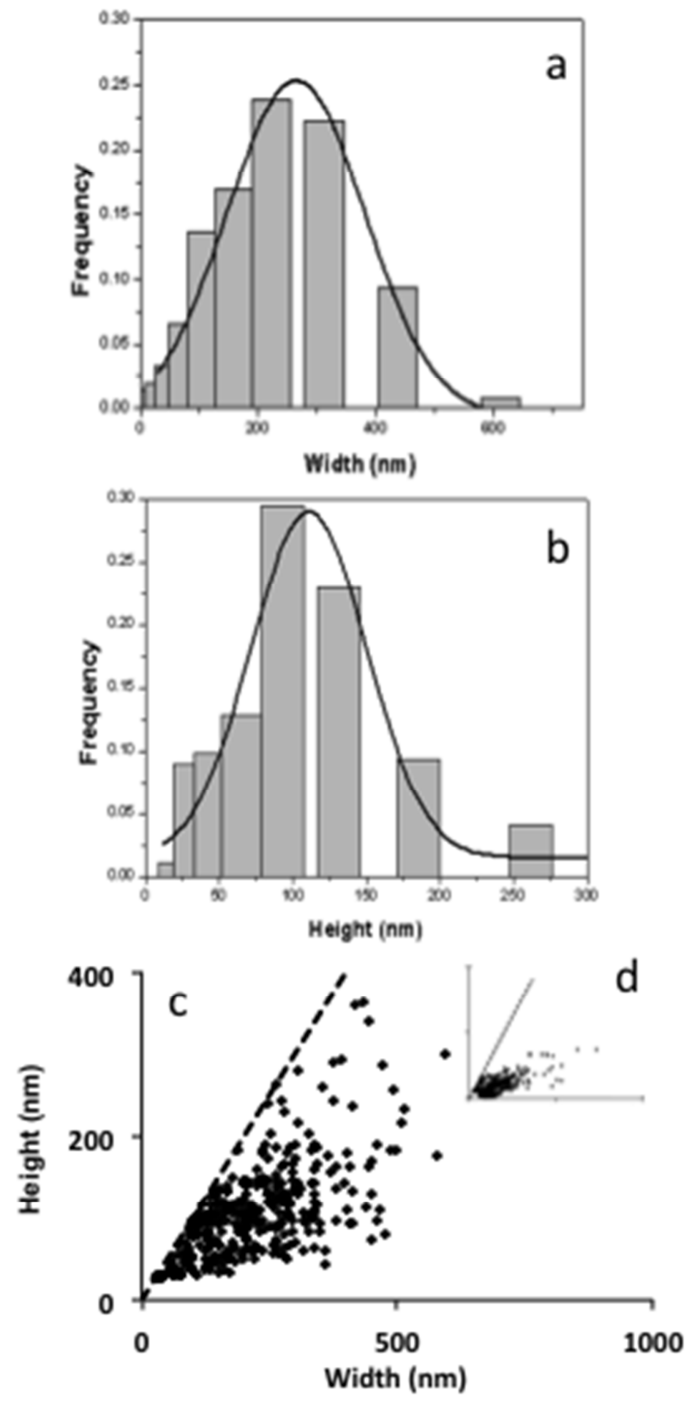
Figure 5

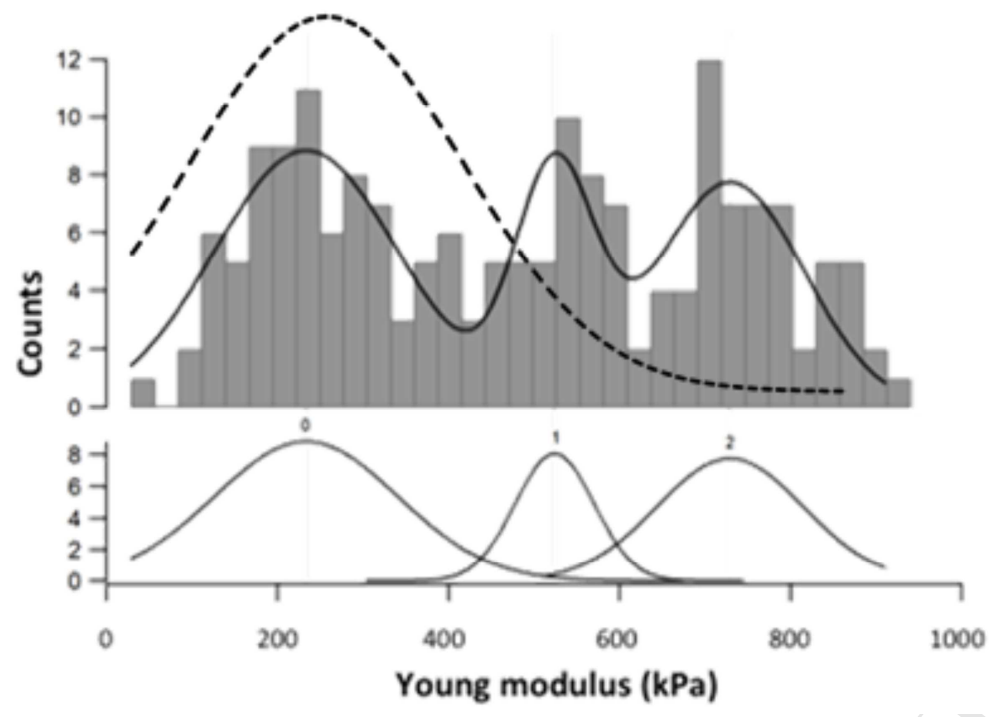




\section{Highlights}

- TG cross-linked CM topography and nanomechanics were evaluated by AFM in liquid.

- TG cross-linked CM are significantly wider and higher than native CM.

- TG-CM are less flattened once captured on gold substrate compared to native CM.

- TG-CM stiffness distribution is multimodal with stiffer peaks compared to native CM. 